\title{
Use of biological drugs in patients with psoriasis and psoriatic arthritis in Italy: Results from the PSONG survey
}

\author{
Maria C. Potenza ${ }^{1}$ | Ketty Peris ${ }^{2}$ | Enzo Berardesca ${ }^{3}$ | Luca Bianchi $^{4}$ | \\ Antonio Richetta ${ }^{4,5}$ | Nicoletta Bernardini ${ }^{1}$ | Clara De Simone ${ }^{2}$ | Miriam Teoli ${ }^{4}$ | \\ Arianna Zangrilli4 $^{4}$ | Sara D'epiro5 ${ }^{5}$ | Diego Orsini6 | Alessandra Narcisi6,7 | \\ Sergio Chimenti ${ }^{4}$ | Antonio Costanzo7,8
}

${ }^{1}$ UOC di Dermatologia "Daniele Innocenzi", Università degli Studi "Sapienza" Roma I facoltà di Medicina e Chirurgia, Polo Pontino, Terracina, LT, Italy

${ }^{2}$ Istituto di Dermatologia Policlinico Gemelli, Rome, Italy

${ }^{3}$ Ambulatorio Psoriasi IFO-San Gallicano, Rome, Italy

${ }^{4}$ Clinica Dermatologica, Dipartimento di Medicina dei Sistemi, Universita Tor Vergata, Rome, Italy

${ }^{5}$ Centro psoriasi, Dipartimento di Medicina Interna e Specialità Mediche, Università

"La Sapienza" Policlinico Umberto I,

Rome, Italy

${ }^{6}$ Clinica Dermatologica, Dipartimento di Neuroscienze Salute Mentale e Organi di Senso (NESMOS), Università SapienzaAzienda Ospedaliera Sant'Andrea, Rome, Italy

${ }^{7}$ Humanitas Clinical and Research Center, Skin Pathology Lab, Rozzano-Milan, Italy

${ }^{8}$ Dermatology Unit, Department of Biomedical Sciences, Humanitas University, Rozzano-Milan, Italy

\section{Correspondence}

Antonio Costanzo, Dermatology Unit, Department of Biomedical Sciences, Humanitas University, IRCCS Istituto Clinico Humanitas, Via Alessandro Manzoni 113, 20089 Rozzano-Milan, Italy. Email: antonio.costanzo@hunimed.eu

Funding information

Fondazione Roma EU2020 INNODERM consortium; Italian Ministry of Health project, Grant/Award Number: CO-201302356463

\begin{abstract}
This Italian multicenter retrospective study compared the drug survival and efficacy of different anti-TNF agents in psoriasis ( $\mathrm{PsO}$ ) and psoriatic arthritis (PsA) patients. A database of PsO/PsA patients treated with adalimumab, etanercept, and infliximab from May 2013 to May 2014 was analyzed. PASI 75, 90, and 100 was calculated at each time point to evaluate efficacy. Drug survival rate and probability of maintaining PASI response were evaluated. The impact of dependent variables on probability of PASI 75 loss was evaluated by logistic regression. 1,235 patients were included, 577 with PsO and 658 with PsA. Highest survival rates were observed with adalimumab followed by etanercept and infliximab in PsO and PsA patients. The probability of maintaining PASI response was significantly higher for adalimumab followed by infliximab. For PsO patients, the odds of losing PASI 75 was higher in etanercept-treated patients (OR: 8.1; 95\% Cl: 4.2-15.6, $p<.001$ ) or infliximab (OR: 6.6; 95\% Cl: $2.6-16.3, p<.001$ ) vs. adalimumab. Likewise, for PsA patients the odds of losing PASI 75 was higher in etanercept-treated patients (OR: $2.3 ; 95 \% \mathrm{Cl}$ : 1.4-3.8, $p=.01$ ) or infliximab (OR: $2.2 ; 95 \% \mathrm{Cl}: 1.1-4.1, p=.018$ ) vs. adalimumab. Adalimumab could be the best therapeutic option over other anti-TNF agents for the treatment of PsO and PsA patients.
\end{abstract}

KEYWORDS

adalimumab, biological drugs, etanercept, infliximab, psoriasis, psoriatic arthritis 


\section{1 | INTRODUCTION}

Psoriasis ( $\mathrm{PsO}$ ) and psoriatic arthritis ( $\mathrm{Ps}$ ) are chronic and invalidating diseases affecting $1-3 \%$ and $0.16-0.25 \%$ of the world population, respectively (Haddad \& Chandran, 2012). Psoriasis is an inflammatory skin disease requiring lifelong care; plaque psoriasis being the most common form ( $90 \%$ ), characterized by painful and itchy erythematous plaques, usually covered with flaking silver scales and localized on scalp, elbows, and knees or generalized disease across wider areas of the body (Canadian Psoriasis Guidelines Committee, 2009; Menter, Gottlieb, and Feldman, 2008). PsA is a chronic inflammatory seronegative spondyloarthropathy associated with PsO (Gottlieb, Korman, \& Gordon, 2008; Scottish Intercollegiate Guidelines Network (SIGN), 2010), with an estimated prevalence in PsO patients of 2540\% (Gottlieb \& Dann, 2009; Laws, Barton, and Warren, 2010). The visible plaques of $\mathrm{PsO}$ have a strong impact on physical and mental functions similar to that of other severe chronic diseases,(Rapp, Feldman, Exum, Fleischer, \& Reboussin, 1999) with high levels of stress, poor self-esteem, increased rates of mood disorders and detrimental effects on social functioning, interpersonal relationships and productivity (Eghlileb, Davies, \& Finlay, 2007). PsA patients may develop severe skeletal changes in addition to cutaneous signs, with a negative impact on function and quality of life (Gossec \& Smolen, 2015). A delay in the diagnosis of PsA that is associated with adverse long term outcome, such as joint damages and associated disabilities; the early detection of PsA can prevent these significant complications (Gossec \& Smolen, 2015; McHugh, 2015).

Treatment strategies of severe or refractory/recalcitrant PsO/PsA recommended by International and National Guidelines are based on disease-modifying drugs (DMARDs), such as methotrexate and cyclosporine. In cases of inadequate response, contraindication or intolerance to at least one DMARD, a therapy with a biologic drug such as tumor necrosis factor (TNF) inhibitors (adalimumab, infliximab, etanercept, golimumab) or anti-interleukin therapies (ustekinumab) should be considered (Canadian Psoriasis Guidelines Committee, 2009; Gossec \& Smolen, 2015; Gossec, Smolen, and Gaujoux-Viala, 2012; II Trattamento della Psoriasi Nell'adulto, 2013; Menter et al., 2008; NICE Clinical Guideline Centre, 2012; Salvarani, Pipitone, and Marchesoni, 2011; Scottish Intercollegiate Guidelines Network (SIGN), 2010). Furthermore, in February 2016, adalimumab was approved by the European Medicines Agency for the treatment of moderate to severe chronic plaque psoriasis in adult patients who are candidates for systemic therapy and not only after previous inadequate response/intolerance to systemic DMARDs (European Medicines Agency, 2016).

TNF, a pleiotropic cytokine which regulates several inflammatory reactions and immune functions through the control of cellular processes, plays a central role in the pathogenesis of PsO and PsA. The over-expression of TNF is able to promote pro-inflammatory conditions and is involved in several pathogenetic mechanisms such as the accumulation of leukocytes in the inflamed skin, induction of dermal vascular changes and itching, and inflammation and joint-bone damage (Blandizzi et al., 2014). TNF inhibitors represent effective therapeutic options for the treatment of $\mathrm{PsO}$ and $\mathrm{PsA}$, significantly improving signs and symptoms and reducing the disease activity. These drugs represent an outstanding innovation in the treatment of inflammatory immunomediated diseases and an important option for modifying the natural course and the unfavorable progression of these diseases (Blandizzi, 2013; Furst, Keystone, and Braun, 2012; Raval, Lofland, Waters, \& Piech, 2011). The anti-TNF agents adalimumab, etanercept and infliximab are indicated both in PsA and PsO (Enbrel ${ }^{\circledR}$ (Etanercept), 2015; Humira ${ }^{\circledR}$ (Adalimumab), 2015; Remicade ${ }^{\circledR}$ (Infliximab), 2015; Simponi ${ }^{\circledR}$ (Golimumab), 2015; Stelara ${ }^{\circledR}$, (ustekinumab), 2015).

National registries provide clinical data from the real-world setting, with the main aim to monitor long-term safety of specific treatments in the clinical setting, but they also contain other important information difficult to collect in clinical trials, such as drug usage, real-life longterm effectiveness, the impact on quality of life (QoL), and related economic issues (Armuzzi et al., 2014).

The aim of this retrospective study was to collect epidemiological and management information on PsO/PsA patients treated with TNF inhibitors in real life. Real life data reflect the daily clinical practice, differently from randomized clinical trials, where stricter inclusion/exclusion criteria are adopted for selecting study populations.

\section{2 | MATERIALS AND METHODS}

\section{1 | Patients and study design}

PSONG was a retrospective longitudinal non-interventional epidemiological investigation performed by consulting a clinical database of PsO/PsA patients treated with biological drugs in 6 centers of Lazio region (Gemelli Polyclinic, Rome; "Daniele Innocenzi" Polo Pontino Dermatology Operating Unit, "La Sapienza" University, Rome; Psoriasis Centre, "La Sapienza" University, "Umberto I" Polyclinic, Rome; "La Sapienza" University S. Andrea, Rome; Psoriasis Clinic ISO Centre, S. Gallicano, Dermatology Unit, Tor Vergata Hospital, Rome) between May 2013 and May 2014. Anti-TNF agents administered to patients included etanercept, infliximab, and adalimumab at common doses (prescribed within the EU). All biologics were administered according to product guidelines (European Medicines Agency, 2016). Inclusion criteria included: male or female patients diagnosed with psoriasis or psoriatic arthritis currently being treated with an anti-TNF agent; patients $\geq 18$ years and patients that have signed an informed consent form. Diagnosis of psoriasis and psoriatic arthritis was clinical. Psoriasis was diagnosed according to the criterion of the "rule of tens" by Finlay (BSA involved $>10 \%$ or PASI score $>10$ or DLQI score $>10$ ) (Finlay, 2005) and all PsA patients met the CASPAR (CIASsification criteria for Psoriatic ARthritis) criteria for the classification of PsA (Taylor, Gladman, \& Helliwell, 2006). The database was designed to record demographic and anamnestic data, concomitant diseases, current and previous biologic treatments, Psoriasis Area Severity Index (PASI) score during the observational period (visits: 0, 3 months, 6 months, 1, 2, 3, 4, 5, 6, 7, 8 years). Ethics committee approval from all participating centers and written informed consent for the anonymous use of personal data was obtained from every patient, in compliance with Legislative Decree 196/2003. This study complies with the ethical standards laid down in the 1975 Declaration of Helsinki. 


\subsection{Outcome measures}

To evaluate the efficacy of each anti-TNF agent, the response rate of a 75\%, 90\%, and 100\% improvement in the PASI score (respectively PASI 75, PASI 90, and PASI 100) was calculated at each time point. The survival rate and probability of maintaining PASI 75,90 , and 100 responses were evaluated for each treatment over the entire observation period.

\section{3 | Statistical analysis}

Data are presented as mean \pm standard deviation for continuous variables, and absolute and relative frequency distribution for categorical data. Comparisons between groups were performed by the Chisquared test for categorical variables and the Wilcoxon test for nonparametric continuous variables. The survival rate for each biologic treatment and time to losing the PASI targets (PASI 75/90/100) were estimated by means of Kaplan-Meier survival curves. The comparison between drug survival rates was performed using the Log-rank test. Linear regression for repeated measures was applied to evaluate the association between the number of patients achieving PASI 75/90/100 among the different biological drugs. All analyses were stratified according to disease type ( $\mathrm{PsO}$ or PsA). $p<.05$ was considered statistically significant. All analysis was performed using SAS version 8.2 for Windows or Stata 12.

\section{3 | RESULTS}

\section{1 | Baseline demographic and clinical characteristics}

A total of 1,235 patients were included in the PSONG study, 577 in the $\mathrm{PsO}$ group and 658 in the PsA group. Patient clinical and demographic characteristics are presented in Supporting Information Table S1. There were a higher proportion of male patients in both the PsO (71.3\%) and PsA (57.1\%) groups. PsA patients were slightly older ( 55 vs. 50 years) and PASI score was higher in PsO patients (range 1118 vs. $4-14$ ). Clinical characteristics prior to initial anti-TNF treatment were well matched across groups (Supporting Information Table S1).

\section{2 | Probability of maintaining treatment}

In $\mathrm{PsO}$ patients the probability of maintaining treatment over the 8year follow-up period was highest in those treated with adalimumab compared to those treated with etanercept $(p=.061)$ or infliximab $(p<.001)$ (Figure 1a). At 6 years, the probability of maintaining adalimumab treatment $(0.62 ; 95 \% \mathrm{Cl}: 0.52-0.7)$ was approximately $10 \%$ higher than etanercept $(0.49 ; 95 \% \mathrm{Cl}: 0.42-0.56)$ and about $30 \%$ higher than infliximab $(0.33$; $95 \% \mathrm{Cl}$ : 0.21-0.44).

In PsA patients, although patients treated with etanercept had a similar probability of maintaining treatment compared to adalimumab at 2 years (0.76; $95 \% \mathrm{Cl}: 0.72-0.80$ vs. 0.74 ; $95 \% \mathrm{Cl}$ : 0.68-0.79, respectively), adalimumab-treated patients had higher probability of maintaining treatment for the remainder of the follow-up period (Figure 1b). As expected, no statistically significant difference was noted between the probability of maintaining treatment for these 2 groups $(p=.91)$, over (a)

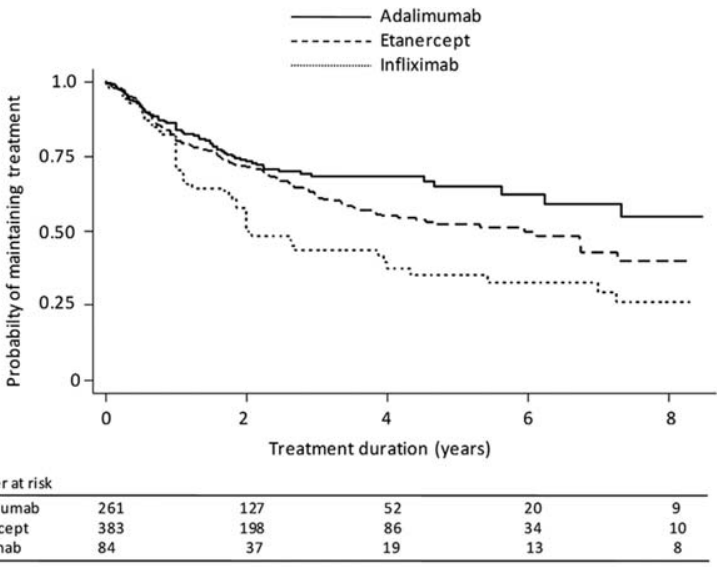

(b)

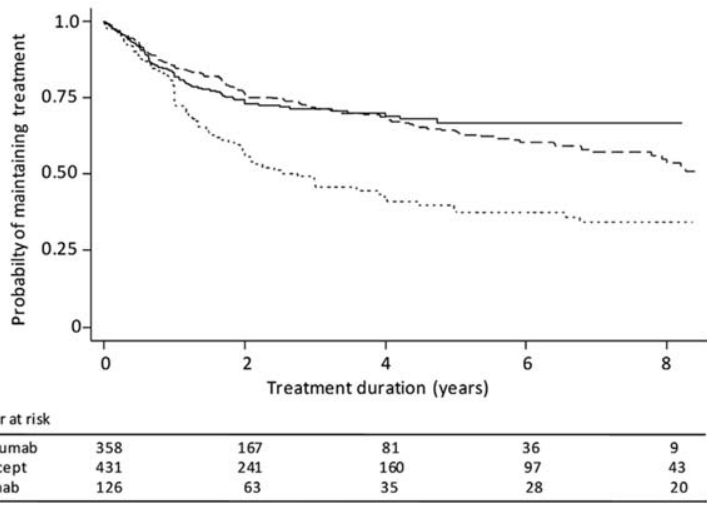

FIGURE 1 Drug survival rates of 3 different anti-TNF agents in $\mathrm{PsO}$ and Psa patients

the entire follow-up period however, infliximab treated patients revealed significantly lower probability of maintaining treatment compared to adalimumab $(p<.001)$ and etanercept $(p<.001)$.

\subsection{Probability of maintaining PASI 75, 90, and 100}

The probability of the 3 different anti-TNF therapies maintaining PASI 75, 90, and 100 for PsO, and PsA patients are summarized in Figure 2. $\mathrm{PsO}$ patients treated with adalimumab had a significantly higher probability of maintaining PASI 75,90 , and 100 compared to etanercept or infliximab (Figure 2a-c). The probability of maintaining PASI 75 was higher for adalimumab compared to etanercept $(p<.001)$ or infliximab $(p=.05)$ (Figure 2a). Similarly, adalimumab was more effective in maintaining PASI 90 compared to etanercept $(p<.01)$ or infliximab $(p=.002)$ (Figure $2 b)$. This trend was also observed for PASI 100, where adalimumab was more effective compared with etanercept $(p<.01)$ or infliximab $(p<.01)$ (Figure 2c). The magnitude of the difference between adalimumab can be reflected in the difference in probability at 4 years compared to etanercept $(0.57 ; 95 \% \mathrm{Cl}$ : $0.43-0.69$ vs. 0.098 ; 95\% Cl: 0.04-0.20). In PsA patients, apart from PASI 75 (Figure 2d), adalimumab was superior in maintaining PASI 90 and 100 compared to etanercept or infliximab. For maintenance of PASI 90, adalimumab was more effective compared with etanercept $(p=.044)$ or infliximab $(p=.024)$ (Figure 2e). This difference was also maintained for PASI 100 
(a)

\section{PSO}

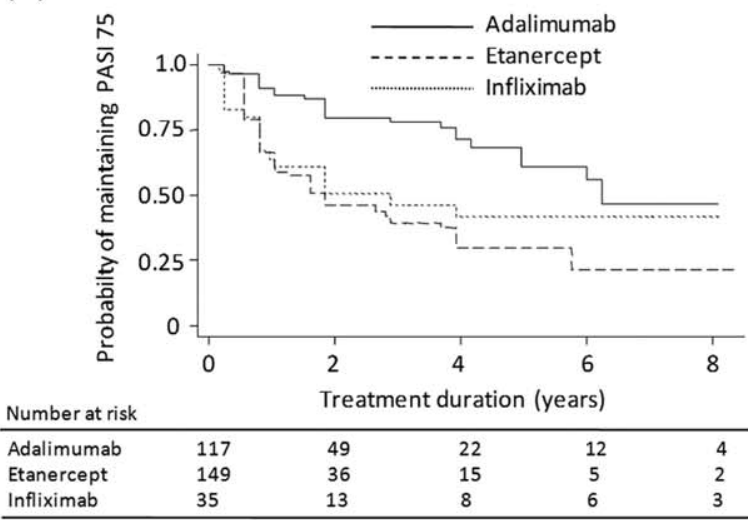

(b)

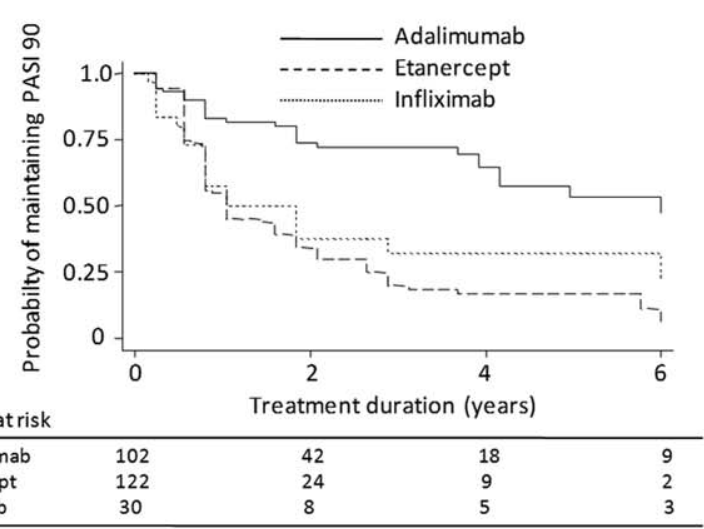

(d)

PSA

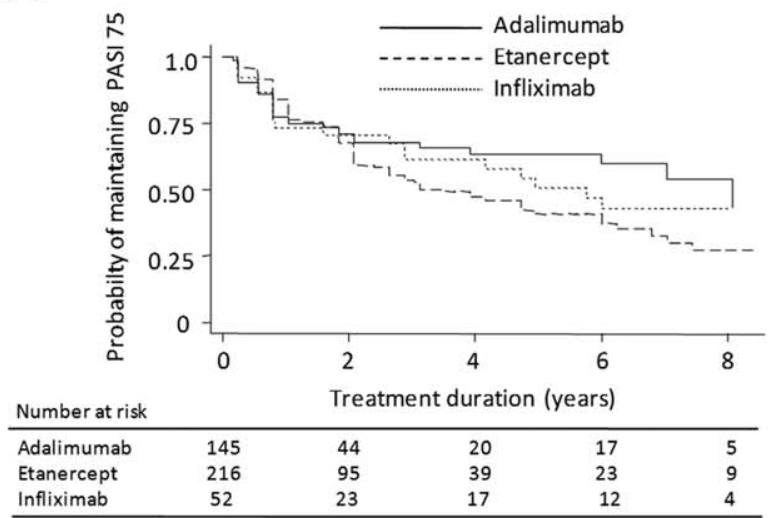

(e)

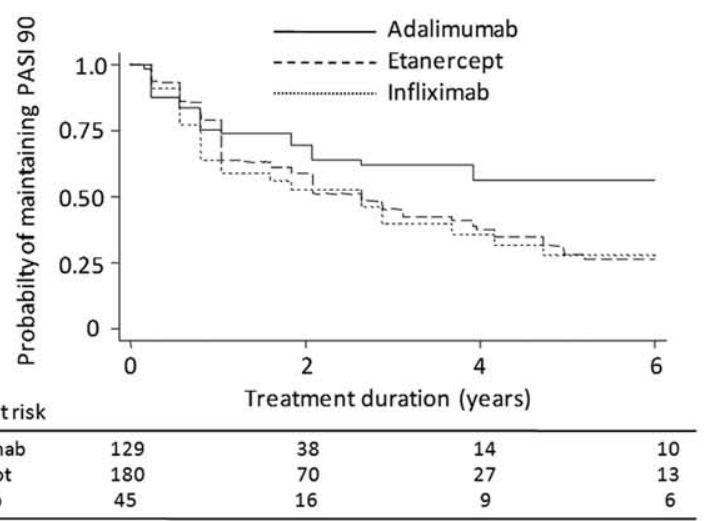

(f)

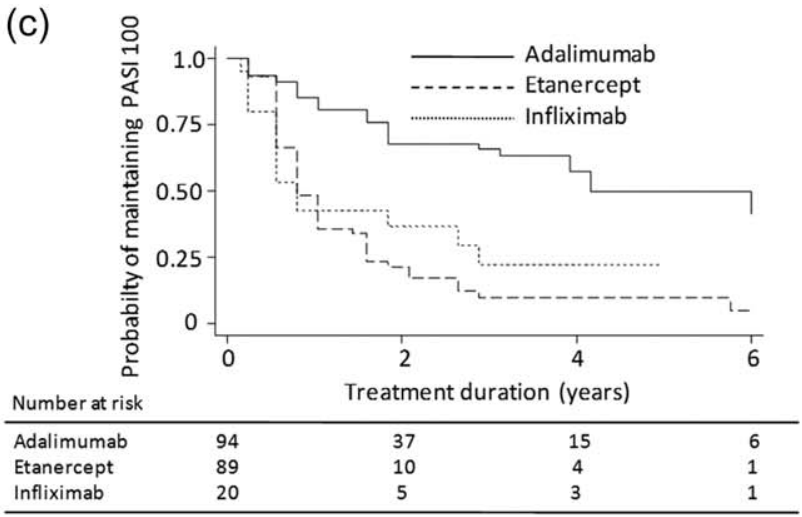

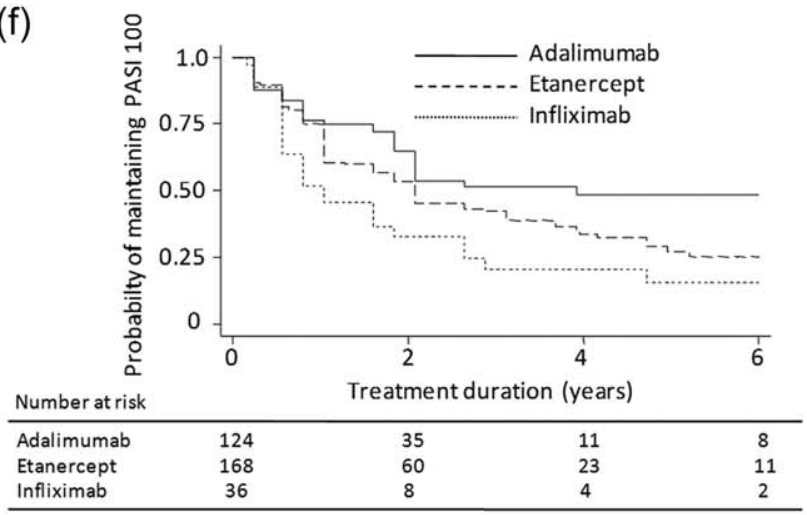

FIGURE 2 Probability of maintaining PASI 75, 90 and 100 in PsO and PsA patients

where a statistically significant difference was observed between adalimumab and etanercept $(p=.050)$ or infliximab $(p<.01)$ (Figure 2f).

\section{4 | PASI clinical response rate}

The clinical response was evaluated as the rate of patients attaining PASI 75, 90, or 100 over the 7 year follow up period. Figure 3 shows the rate of $\mathrm{PsO}$ and PsA patients with PASI 75, 90, and 100 response stratified by anti-TNF treatment. The proportion of PsO patients with PASI 75 over the follow up period was higher for adalimumab vs. etanercept and infliximab (Figure 3a). Similarly, a higher proportion of patients attained PASI 90 treated with adalimumab compared to etanercept or infliximab as well as those patients with PASI 100 (Figure 3b,c). In contrast, in PsA patients, no differences in terms of PASI 75 response rate were observed among the three treatments (Figure 3d). PASI 90 and PASI 100 responses were markedly higher in patients treated with adalimumab compared with patients treated with etanercept (Figure 3e,f). A higher PASI 100 response rate was observed for adalimumab vs. infliximab (Figure 3f).

\subsection{Impact of predictor variables on PASI 75 loss}

Logistic regression analysis was used to evaluate the impact of independent variables on the probability of PASI 75 loss in the PsO 

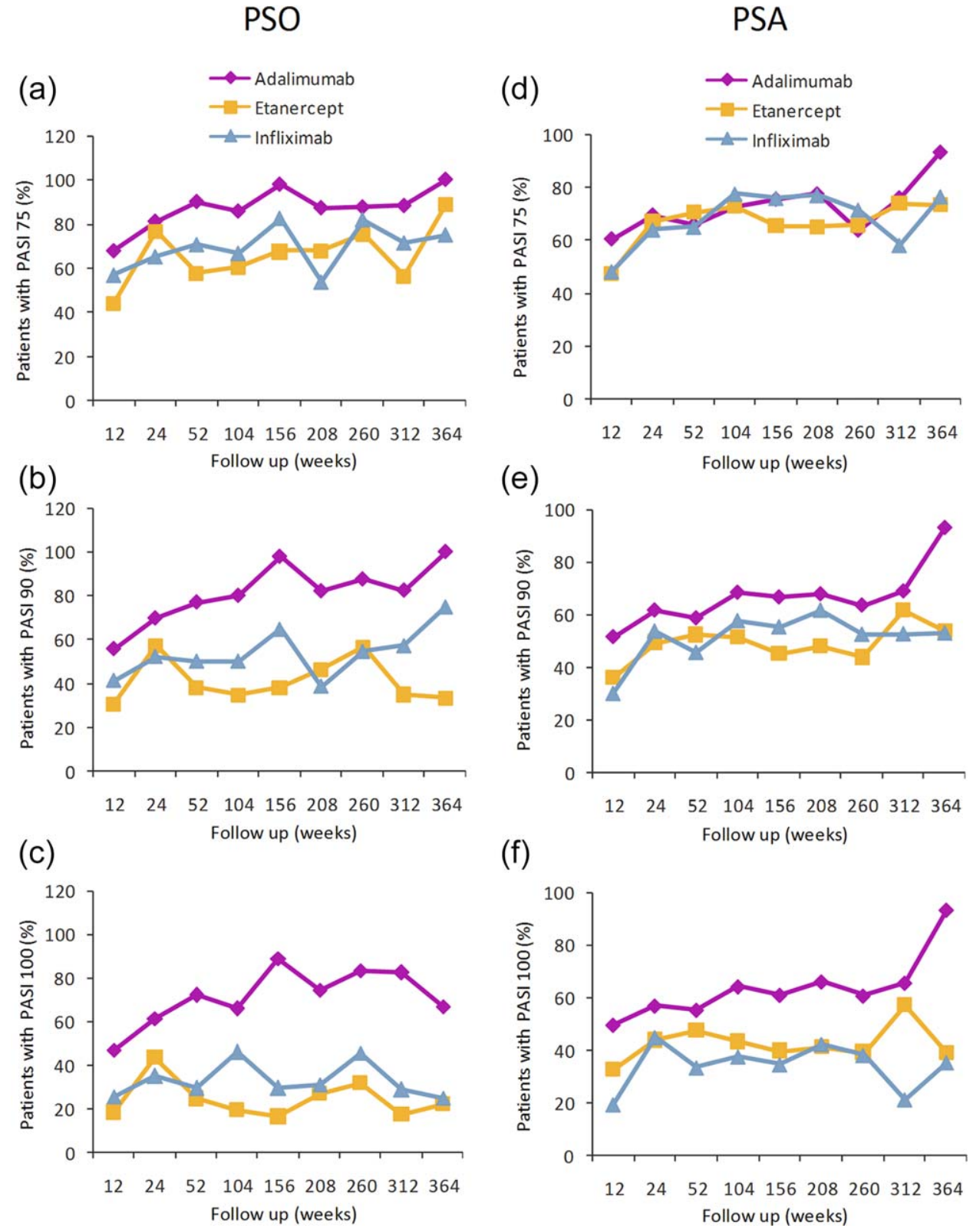

(f)

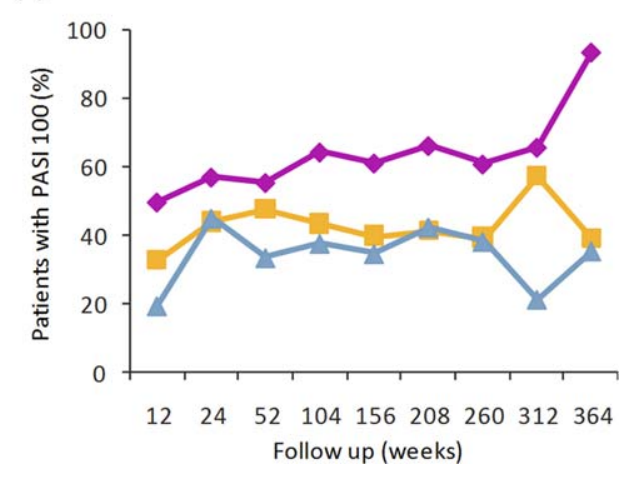

FIGURE 3 PASI clinical response rate in PsO and PsA patients

and PsA groups (Supporting Information Table S2, upper panel). In Information Table S2, lower panel). Univariate analysis showed that etanercept and infliximab compared to adalimumab treatment increased the odds of PASI 75 loss by $2.33-(95 \% \mathrm{Cl}$ : 1.4-3.8, $p=.001)$ and 2.32 -fold (95\% Cl: 1.14-4.1, $p=.01)$, respectively. Baseline PASI was not associated with PASI 75 loss. Etanercept (Odds ratio: $2.29,95 \% \mathrm{Cl}: 1.4-3.77, p=.001$ ) and infliximab (Odds ratio: $2.19,95 \% \mathrm{Cl}: 1.14-4.14, p=.018$ ) compared to adalimumab treatment still emerged as significant predictors of PASI 75 loss following multivariate logistic analysis.

\section{DISCUSSION} $16.3, p<.001)$ compared to adalimumab treatment still emerged as strong predictors of PASI 75 loss. The effect of biologic therapy had less of an impact on PASI 75 loss in PsA patients (Supporting

The main outcome measure examined in this retrospective study, carried out in a routine clinical setting using the data of a clinical database of $\mathrm{PsO} / \mathrm{PsA}$ patients treated with biological drugs in 6 Italian centers, 
was the drug survival, which reflects a drug's effectiveness, safety and tolerability. Drug survival is based on several factors such as dosage, effectiveness, improvement of the quality of life, safety and compliance and could be considered an overall marker for treatment success.

Gisondi et al. recently demonstrated that the retention rate (the number of patients who maintain the same therapy during a given period of treatment) of TNF-alpha inhibitors was significantly higher compared with conventional systemic treatment (DMARDs), due to a better tolerability (Gisondi, Tessari, Di Mercurio, Del Giglio, \& Girolomoni, 2013). In fact, the number of patients who discontinued TNFalpha inhibitors was lower than that of DMARDs. No differences were noted among TNF-alpha inhibitors (Gisondi, Tessari, \& Di Mercurio, 2013). An Italian experience (BEETLE study) evaluated 1,219 patients included in administrative databases of five Italian local health units (LHU) in Emilia-Romagna, Lazio, Tuscany, Campania, and Lombardy. Patients were affected by rheumatoid arthritis (36\%), PsO (31\%), Crohn's disease (10\%) and other immune-mediated inflammatory diseases and treated with etanercept $(n=615)$, adalimumab $(n=420)$, and infliximab $(n=184)$. Among the group of patients who did not switch to another drug (94\%), the rate of adherence across all indications was higher for infliximab (51\%) compared to etanercept (27\%) or adalimumab (23\%) (Degli Esposti, Sangiorgi, \& Perrone, 2014).

Our results show that in $\mathrm{PsO}$ patients, adalimumab has the highest survival rate, statistically superior to that of etanercept and infliximab. These results are partially in contrast with other recent epidemiological surveys (Esposito, Gisondi, \& Cassano, 2013; Gniadecki, Kragballe, Dam, \& Skov, 2011; Gniadecki, Bang, and Bryld, 2015).

The retrospective study Outcome and Survival Rate Concerning Anti-TNF Routine treatment (OSCAR) showed that etanercept had a longer survival (mean 51.4 months, $p<.001$ ) compared with infliximab (36.8 months) and adalimumab (34.7 months) (Esposito et al., 2013). Gniadecki et al. evaluated the data of the Danish prospective nationwide database DERMBIO (registry for PsO patients showing that in the group of anti-TNF-a-naive patients, the longest drug survival was observed for infliximab, followed by adalimumab and etanercept (Gniadecki, Kragballe, \& Dam, 2011). A recently published update of this study included 1,867 treatment series over a period of 10 years. In this study, drug survival was significantly longer for ustekinumab than for the anti-TNF-alpha inhibitors $(p<.001)$. In particular, adalimumab and infliximab had comparable median survival rates and etanercept had the shortest survival time (Gniadecki et al., 2015).

Our data confirmed previously reported data from several registrybased studies (Brunasso, Puntoni, \& Massone, 2012; Iskandar, et al. 2015May18; Menting, Sitaram, \& Bonnerjee-van der Stok, 2014; van den Reek et al., 2014; Warren et al., 2015). In a retrospective cohort study evaluating tolerability and safety of biological drugs (adalimumab, efalizumab, etanercept, and infliximab) in $108 \mathrm{PsO}$ patients infliximab was significantly associated with a shorter adherence to therapy compared with adalimumab, etanercept, and efalizumab (Brunasso et al., 2012). The British Association of Dermatologists Biologic Interventions Register (BADBIR) is a prospective, observational database designed to evaluate the long-term safety of biologic and conventional systemic treatments for adults with moderate-to-severe PsO in the U.K. and
Republic of Ireland. 5,065 (60\%) out of 8,399 patients included in BADBIR received a biologic drug: $52.8 \%$ adalimumab, $24.6 \%$ etanercept, 18.7\% ustekinumab, and 3.9\% infliximab (Iskandar et al., 2015). Warren et al. calculated the survival rates of the first course of biologics for 3523 biologic-naïve patients with chronic plaque $\mathrm{PsO}$ enrolled in BADBIR database. The overall survival rate in the first year was $77 \%$ and $53 \%$ in the third year. In particular, patients treated with etanercept or infliximab were more likely to discontinue therapy compared with adalimumab or ustekinumab (Warren et al., 2015). Similar results were observed in Bio-CAPTURE (Continuous Assessment of Psoriasis Treatment Use Registry with biologics) registry, implemented by the department of Dermatology of the Radboud University Medical Center, Nijmegen in 2005. The results of these trials showed that the 1-year drug survival rates for ustekinumab, adalimumab, and etanercept were $85 \%, 74 \%$, and $68 \%$, respectively (van den Reek et al., 2014). Finally, a single center database analysis performed in the Academic Medical Center, Amsterdam, the Netherlands, on $221 \mathrm{PsO}$ patients treated with biological drugs showed no statistically significant differences in terms of drug survival, either in naive episodes (etanercept $82-52 \%$, adalimumab $75-80 \%$, infliximab $73-57 \%$ after year $1-4$ ), or in non-naive episodes (etanercept $77-31 \%$, adalimumab $75-44 \%$, infliximab $65-43 \%$ after year 1-4, ustekinumab 80-25\% after year 1-3) (Menting et al., 2014).

According to our data, in PsA patients the probability of remaining in treatment was higher for adalimumab, significantly lower for etanercept, followed by infliximab. Our findings contrast with those in other reports. The retrospective study by Fabbroni et al. evaluated treatment persistence rates and causes of discontinuation in 268 PsA and ankylosing spondylitis patients treated with biological drugs in clinical practice (Fabbroni, Cantarini, \& Caso, 2014). The comparison among the 3 anti-TNF drugs showed a difference in terms of drug survival: a withdrawal was required in $28.9 \%$ of patients treated with adalimumab, $22.8 \%$ of patients treated with etanercept and in $38.2 \%$ of those treated with infliximab; the difference between etanercept and infliximab was statistically significant ( $p=.0058$ ) (Fabbroni et al., 2014). An epidemiological observational cohort study from The Danish biologics registry DANBIO evaluated the patients' clinical response and drug survival to anti-TNF-alpha inhibitors of 764 PsA patients (Glintborg, Østergaard, \& Dreyer, 2011). The results showed that the median drug survival was 2.9 years, and 1-year and 2-year drug survival rates were $70 \%$ and $57 \%$, respectively. In particular, no differences were observed in terms of retention rates, which were similar among patients receiving infliximab, adalimumab and etanercept (Glintborg et al., 2011).

Considering the efficacy outcome based on PASI response and the survival rate, in our experience adalimumab was the most effective treatment both in PsO and in PsA patients. These efficacy results are similar to or even higher than those reported in clinical trials (Armesto, Coto-Segura, Mayorga, Illaro, \& Santo-Juanes, 2015; Esposito, Giunta, and Mazzotta, 2012; Gordon et al., 2012; Lopez-Ferrer, Vilarrasa, Gich, \& Puig, 2013; Menter et al., 2008; Papp, Ho, and Teixeira, 2012; Papp, et al. 2009September-October). Some recent meta-analyses and direct/ indirect comparisons evaluated the effectiveness of available biological drugs in PsO and PsA patients. Overall, the results showed that there were no significant differences between the drugs in relation to the 
efficacy outcomes, except for a superiority of ustekinumab, adalimumab and infliximab versus etanercept in terms of PASI response in PsO patients (Galvan-Banqueri, Marín Gil, Santos Ramos, \& Bautista Paloma, 2013; Puig, Lopez, Vilarrasa, \& García, 2014; Reich, Burden, Eaton, \& Hawkins, 2012; Schmitt, Rosumeck, and Thomaschewski, 2014).

Taken together, these results confirm that adalimumab is a valid therapeutic options for the long term management of severe-tomoderate $\mathrm{PsO}$ and PsA patients, as recommended by International and National guidelines. Furthermore, adalimumab is the only anti-TNF agent approved for first line treatment of moderate to severe chronic plaque psoriasis in adult patients (16). It is noteworthy that biological drugs are often combined with traditional therapies in daily clinical practice: this aspect should be further evaluated in clinical trials, as well as the clinical response in $\mathrm{PsO}$ and $\mathrm{PsA}$ biologic experienced vs. naïve patients.

\section{1 | Study strengths and limitations}

This study is of particular value as it provides longitudinal data (collected retrospectively) from 1,235 patients, (577 in the $\mathrm{PsO}$ group and 658 in the PsA group) from 6 centers with follow-up times ranging from 6 months to 8 years. To date, few studies are available that report data on this Italian population. However, there are some potential limitations that need to be addressed. Weaknesses of observational registries such as the reliability of results and incompleteness of data have previously been highlighted (Vandenbroucke, von Elm, and Altman, 2007; von Elm, Altman, and Egger, 2007). Furthermore, the lack of randomization may also introduce selection bias, and the presence of unmeasured confounders cannot always be ruled out. However, we did not observe any marked changes in clinical characteristics among treatment groups attributed to loss during follow-up. This potential limitation was also addressed by including potential confounding variables in logistic regression models. It is recognized that efficacy and retention in therapy for biologics is correlated with line of treatment. Although the proportion of naive patients was not markedly different in the PsO (50-65\%) and PsA groups (30-55\%), our analysis did not specifically examine efficacy by line of treatment, which was not feasible due to the low sample sizes for this subanalysis. Last, our analysis was limited to the comparison of adalimumab, etanercept, and infliximab for the treatment of PsO and PsA patients. Few patients were treated with golimumab $(N=47)$ to permit further analysis and certolizumab was not available in Italy at the time this study was undertaken.

\section{5 | CONCLUSIONS}

Real-life data, typically collected by national registers and noninterventional studies, represent an important source of information on long-term treatment, efficacy and safety in day-to-day conditions of clinical practice and among heterogeneous groups of patients, such as elderly subjects or patients with comorbidities or co-medications, usually excluded from randomized controlled trials.

\section{ACKNOWLEDGMENTS}

AC served as speaker for Janssen, Abbvie, Pfizer, Celgene, Lilly, Novartis. LB served as speaker for Abbvie, Pfizer, Celgene. SDE Janssen, Abbvie, Pfizer, Celgene, Lilly, Novartis. AR served as speaker for Abbvie. KP served as speaker for Janssen, Abbvie, Pfizer, Celgene, Lilly, Novartis. CDS served as speaker for Janssen, Abbvie, Pfizer, Celgene, Lilly, Novartis. This work was supported in part by grants from Fondazione roma grant n. NCDS-2013-00000318, EU2020 European Commission H2020 grant agreement n. 687866, INNODERM consortium, Ministero della Salute project CO-201302356463.

\section{CONFLICT OF INTEREST}

AC served as speaker for Janssen, Abbvie, Pfizer, Celgene, Lilly, Novartis.

\section{ORCID}

Antonio Costanzo (iD http://orcid.org/0000-0001-9697-2557

\section{REFERENCES}

Armesto, S., Coto-Segura, P., Mayorga, J., Illaro, A., \& Santo-Juanes, J. (2015). Efficacy of adalimumab in the treatment of moderate-tosevere psoriasis: A retrospective study of 100 patients in daily practice. Journal of Dermatological Treatment, 26, 49-53.

Armuzzi, A., Lionetti, P., Blandizzi, C., Caporali, R., Chimenti, S., Cimino, L., ...Cimaz, R. (2014, January-March). Anti-TNF agents as therapeutic choice in immune-mediated inflammatory diseases: Focus on adalimumab. International Journal of Immunopathology Pharmacology, 27(1 Suppl), 11-32.

Blandizzi, C., Gionchetti, P., Armuzzi, A.,Caporali, R., Chimenti, S., Cimaz, R., ... Girolomoni, G. (2014, January-March). The role of tumour necrosis factor in the pathogenesis of immune-mediated diseases. International Journal of Immunopathology Pharmacology, 27(1 Suppl), 1-10.

Blandizzi, C., SOCIETA' ITALIANA DI FARMACOLOGIA. (2013). Equivalenza terapeutica di classe dei farmaci inibitori del tumour necrosis factor: analogie e differenze farmacologiche. Position paper. Retrieved from http://www.sifweb.org/docs/sif_position_paper_anti_ tnf_giu13.pdf

Brunasso, A. M. G., Puntoni, M., \& Massone, C. (2012). Drug survival rates of biologic treatments in patients with psoriasis vulgaris. British Association of Dermatologists, 166, 447-449.

Canadian Psoriasis Guidelines Committee. (2009, June). Canadian guidelines for the management of plaque psoriasis.. Retrieved from http:// www.dermatology.ca/psoriasisguidelines

Degli Esposti, L., Sangiorgi, D., Perrone, V., Radice, S., Clementi, E., Perone, F., \& Buda, S. (2014). Adherence and resource use among patients treated with biologic drugs: findings from BEETLE study. ClinicoEconomics and Outcomes Research, 6, 401-407.

Eghlileb, A. M., Davies, E. E. G., \& Finlay, A. Y. (2007). Psoriasis has a major secondary impact on the lives of family members and partners. British Journal of Dermatology, 156, 1245-1250.

Enbrel ${ }^{\circ}$ (Etanercept). (2015). [Summary of product characteristics]. Retrieved from http://www.ema.europa.eu/docs/en_GB/document_ library/EPAR_-_Product_Information/human/000262/WC500027361. pdf 
Esposito, M., Gisondi, P., Cassano, N., Ferrucci, G., Del Giglio, M., Loconsole, F., ... Girolomoni, G. (2013). Survival rate of antitumour necrosis factor-a treatments for psoriasis in routine dermatological practice: A multicentre observational study. British Journal of Dermatology, 169, 666-672.

Esposito, M., Giunta, A., Mazzotta, A., Zangrilli, A., Babino, G., Perricone, R., ... Chimenti, M. S. (2012). Efficacy and safety of subcutaneous anti-tumor necrosis factor-alpha agents, etanercept and adalimumab, in elderly patients affected by psoriasis and psoriatic arthritis: An observational long-term study. Dermatology, 225(4), 312-319.

European Medicines Agency. (2016). Retrieved from http://www.ema. europa.eu/docs/en_GB/document_library/Summary_of_opinion/human/ 000481/WC500202367.pdf

Fabbroni, M., Cantarini, L., Caso, F., Costa, L., Pagano, V. A., Frediani, B., ... Galeazzi, M. (2014). Drug retention rates and treatment discontinuation among anti-TNF- $\alpha$ agents in psoriatic arthritis and ankylosing spondylitis in clinical practice. Mediators Inflammation, 2014, 862969. https://doi.org/10.1155/2014/862969

Finlay, A. Y. (2005). Current severe psoriasis and the rule of tens. British Journal of Dermatology, 152, 861-867.

Furst, D. E., Keystone, E. C., Braun, J., Breedveld, F. C., Burmester, G. R., De Benedetti, G. R., ... Winthrop, K. L. (2012). Updated consensus statement on biological agents for the treatment of rheumatic diseases. Annals of Rheumatic Disorder, 71(Suppl. 2), i2-45.

Galvan-Banqueri, M., Marín Gil, R., Santos Ramos, B., \& Bautista Paloma, F. J. (2013). Biological treatments for moderate-to-severe psoriasis: Indirect comparison. Journal of Clinical Pharmacy and Therapeutics, 38, 121-130.

Gisondi, P., Tessari, G., Di Mercurio, M., Del Giglio, M., \& Girolomoni, G. (2013). Retention rate of systemic drugs in patients with chronic placque psoriasi. Clinical Dermatology, 1(1), 8-14.

Glintborg, B., Østergaard, M., Dreyer, L., Krogh, N. S., Tarp, U., Hansen, M. S., ... Hetland, M. L. (2011). Treatment response, drug survival, and predictors thereof in 764 patients with psoriatic arthritis treated with anti-tumor necrosis factor alpha therapy. Results from the Nationwide Danish DANBIO Registry. Arthritis \& Rheumatism, 63, 382-390.

Gniadecki, R., Bang, B., Bryld, L. E., Iversen, L., Lasthein, S., \& Skov, L. (2015). Comparison of long-term drug survival and safety of biologic agents in patients with psoriasis vulgaris. British Journal of Dermatology, 172, 244-252.

Gniadecki, R., Kragballe, K., Dam, K. N., \& Skov, L.. (2011). Comparison of drug survival rates for adalimumab, etanercept and infliximab in patients with psoriasis vulgaris. British Association of Dermatologists, 164, 1091-1096.

Gordon, K., Papp, K., Poulin, Y., Gu, Y., Rozzo, S., \& Sasso, E. H. (2012). Long-term efficacy and safety of adalimumab in patients with moderate to severe psoriasis treated continuously over 3 years: Results from an open-label extension study for patients from REVEAL. Journal of American Academy of Dermatology, 66, 241-251.

Gossec, L., \& Smolen, J. S. (2015, September-October). Treatment of psoriatic arthritis: Management recommendations. Clinical Experimental Rheumatology, 33(5 Suppl 93), S73-S77.

Gossec, L., Smolen, J. S., Gaujoux-Viala, C., Ash, Z., Marzo-Ortega, H., van der Hejide, D., ...Emery, P., European League Against Rheumatism. (2012). European league against rheumatism recommendations for the management of psoriatic arthritis with pharmacological therapies. Annals of Rheumatic Disorder, 71, 4-12.

Gottlieb, A., \& Dann, F. (2009, December). Comorbidities in patients with psoriasis. The American Journal of Medicine, 122(12), 1150.e1-9.

Gottlieb, A., Korman, N. J., Gordon, K. B., Feldman, S. R., Lebwohl, M., Koo, J. Y., ... Menter, A. (2008). Guidelines of care for the management of psoriasis and psoriatic arthritis: Section 2. Psoriatic arthritis: Overview and guidelines of care for treatment with an emphasis on the biologics. Journal of American Academy of Dermatology, 58, 851-864.

Haddad, A., \& Chandran, V. (2012). How can psoriatic arthritis be diagnosed early?. Currents Rheumatology Reports, 14, 358-363.

Humira ${ }^{\circledR}$ (Adalimumab). (2015). [Summary of product characteristics]. Retrieved from http://www.ema.europa.eu/docs/en_GB/document_ library/EPAR_-_Product_Information/human/000481/WC500050870. pdf

II Trattamento della Psoriasi Nell'adulto. (2013). Sistema nazionale linee guida- Istituto Superiore di Sanità Associazione Dermatologi Ospedalieri Italiani. Maggio.

Iskandar, I. Y. K., Ashcroft, D. M., Warren, R. B., Yiu, Z. Z., McElhone, K., Lunt, M., ... Griffiths, C. E. (2015, May 18). Demographics and disease characteristics of patients with psoriasis enrolled in the British Association of Dermatologists Biologic Interventions Register. British Journal of Dermatology, 173, 510-518. https://doi.org/10.1111/bjd.13908

Laws, P., Barton, A., \& Warren, R. B. (2010). Psoriatic arthritis - What the dermatologist needs to know. Journal of European Academy of Dermatology Venereology, 24, 1270-1277.

Lopez-Ferrer, A., Vilarrasa, E., Gich, I. J., \& Puig, L. (2013). Adalimumab for the treatment of psoriasis in real life: A retrospective cohort of 119 patients at a single Spanish centre. British Journal of Dermatology, $169,1141-1147$.

McHugh, N. J. (2015). Verna Wright lecture: Psoriatic arthritis: The need for early intervention. Journal of Rheumatology Supplement, 93, 10-13.

Menter, A., Gottlieb, A., \& Feldman, S. R. (2008). Guidelines of care for the management of psoriasis and psoriatic arthritis Section 1. Overview of psoriasis and guidelines of care for the treatment of psoriasis with biologics. Journal of American Academy of Dermatology, $58,826-850$.

Menting, S. P., Sitaram, A. S., Bonnerjee-van der Stok, H. M., de Rie, M. A., Hooft, L., \& Spuls, P. I. (2014). Drug survival is not significantly different between biologics in patients with psoriasis vulgaris: A singlecentre database analysis. British Journal of Dermatology, 171, 875-883.

NICE Clinical Guideline Centre. (2012, October). Psoriasis. The assessment and management of psoriasis. National Institute for Health and Clinical Excellence.

Papp, K., Ho, V., Teixeira, H. D., Guerette, B., Chen, K., \& Lynde, C. (2012). Efficacy and safety of adalimumab when added to inadequate therapy for the treatment of psoriasis: Results of PRIDE, an openlabel, multicentre, phase IIIb study. Journal of European Academy of Dermatological Venereology, 26, 1007-1013.

Papp, K., Okun, M., \& Vender, R. (2009, September-October). Adalimumab in the treatment of psoriasis: Pooled efficacy and safety results from three pivotal studies. Journal of Cutaneous Medical Surgery, 13 (Suppl 2), S58-S66.

Puig, L., Lopez, A., Vilarrasa, E., \& García, I. (2014). Efficacy of biologics in the treatment of moderate-to-severe plaque psoriasis: A systematic review and meta-analysis of randomized controlled trials with different time points. Journal of European Academy of Dermatology and Venereology, 28, 1633-1653.

Rapp, S. R., Feldman, S. R., Exum, M. L., Fleischer, A. B., Jr., \& Reboussin, D. M. (1999). Psoriasis causes as much disability as other major medical diseases. Journal of American Academy of Dermatology, 41, 401-407.

Raval, K., Lofland, J. H., Waters, H., \& Piech, C. T. (2011). Disease and treatment burden of psoriasis: Examining the impact of biologics. Journal of Drugs Dermatology, 10, 189-196. 
Reich, K., Burden, A. D., Eaton, J. N., Hawkins, N. S. (2012). Efficacy of biologics in the treatment of moderate to severe psoriasis: A network meta-analysis of randomized controlled trials. British Association of Dermatologists, 166, 179-188.

Remicade ${ }^{\circledR}$ (Infliximab). (2015). [Summary of product characteristics]. Retrieved from http://www.ema.europa.eu/docs/en_GB/document_ library/EPAR__Product_Information/human/000240/WC500050888.pdf

Salvarani, C., Pipitone, N., Marchesoni, A., Cantini, F., Cauli, A., Lubrano, E., ... Olivieri, I., Italian Society for Rheumatology. (2011). Recommendations for the use of biologic therapy in the treatment of psoriatic arthritis: Update from the Italian Society for Rheumatology. Clinical Experimental Rheumatology, 29(Suppl. 66), S28-S41.

Schmitt, J., Rosumeck, S., Thomaschewski, G., Sporbeck, B., Haufe, E., \& Nast A. (2014). Efficacy and safety of systemic treatments for moderate-to severe psoriasis: Meta-analysis of randomized controlled trials. British Journal of Dermatology, 170, 274-303.

Scottish Intercollegiate Guidelines Network (SIGN). (2010). Diagnosis and management of psoriasis and psoriatic arthritis in adults (SIGN publication no. 121). Edinburgh: SIGN. Retrieved from http://www.sign.ac. uk (cited 12 Oct 2010).

Simponi ${ }^{\circ}$ (Golimumab). (2015). [Summary of product characteristics]. Retrieved from http://www.ema.europa.eu/docs/en_GB/document library/EPAR_-_Product_Information/human/000992/WC500052368.pdf

Stelara ${ }^{\circledR}$, (ustekinumab). (2015). [Summary of product characteristics]. Retrieved from http://www.ema.europa.eu/docs/en_GB/document library/EPAR_-_Product_Information/human/000958/WC500058513.pdf

Taylor, W., Gladman, D., Helliwell, P., Marchesoni, A., Mease, P., Mielants, H. The CASPAR Study Group, et al. (2006). Classification criteria for psoriatic arthritis: Development of new criteria from a large international study. Arthritis Rheumatics, 54, 2665-2673.

van den Reek, J. M., Zweegers, J., Kievit, W., Otero, M. E., van Lümig, P. P., Driessen, R. J., ... de Jong, E. M. (2014, November). 'Happy' drug survival of adalimumab, etanercept and ustekinumab in psoriasis in daily practice care: Results from the BioCAPTURE network. British Journal of Dermatology, 171(5), 1189-1196.

Vandenbroucke, J. P., von Elm, E., Altman, D. G., Gøtzsche, P. C., Mulrow, C. D., Pocock, S. J., ... Egger, M., STROBE Initiative. (2007). Strengthening the Reporting of Observational Studies in Epidemiology (STROBE): Explanation and elaboration. Annals of Internal Medicine, 147, W163-W194.

von Elm, E., Altman, D. G., Egger, M., Pocock, S. J., Gøtzsche, P. C., Vandenbroucke, J. P., STROBE Initiative. (2007). The Strengthening the Reporting of Observational Studies in Epidemiology (STROBE) statement: Guidelines for reporting observational studies. Annals of Internal Medicine, 147, 573-577.

Warren, R. B., Smith, C. H., Yiu, Z. Z., Ashcroft, D. M., Barker, J. N. W. N., Burden, A. D., ... Griffiths, C. E. M. (2015, June 8). Differential drug survival of biologic therapies for the treatment of psoriasis: A prospective observational cohort study from the British Association of Dermatologists Biologic Interventions Register (BADBIR). Journal of Investigative Dermatology, 135, 2632-2640. https://doi.org/10. 1038/jid.2015.208

\section{SUPPORTING INFORMATION}

Additional Supporting Information may be found online in the supporting information tab for this article.

How to cite this article: Potenza MC, Peris K, Berardesca E, et al. Use of biological drugs in patients with psoriasis and psoriatic arthritis in Italy: Results from the PSONG survey. Dermatologic Therapy. 2018;31:e12565. https://doi.org/10.1111/dth. 12565 